\title{
Resistance to change: Car use and routines ${ }^{\text {in }}$
}

\author{
Patrizia Lattarulo $^{\mathrm{a}}$, Valentino Masucci ${ }^{\mathrm{b}}$, Maria Grazia Pazienza ${ }^{\mathrm{c}, *}$ \\ ${ }^{a}$ Regional Institute for Economic Planning of Tuscany (IRPET), Italy \\ ${ }^{\mathrm{b}}$ Libera Università degli Studi Sociali, Italy \\ ${ }^{\mathrm{c}}$ Dipartimento di Scienze per l'Economia e l'Impresa, University of Florence, Via delle Pandette, 21, 50127, Florence, Italy
}

\section{A R T I C L E I N F O}

\section{Keywords:}

Urban mobility

Commuter behaviour

Habits

Discrete choice models

\begin{abstract}
A B S T R A C T
The economics literature has shown that individual behaviour is not necessarily driven by rational principles but is mainly influenced by emotional and habit-related factors (Hoffman et al. 2017). An opportunity to test individual transport attitudes was offered by a radical change in the mobility pattern induced for a short period by a big event which took place in Florence, a medium-sized historical Italian city. This event offered an opportunity to analyse how commuters adapted to the transport reorganization, which aimed to prevent car use during the event. We perform an empirical analysis on a sample of employees, comparing transport choices during the event to their stated ordinary behaviour. The paper focuses on analysing the decision to modify transport choice in changed circumstances with particular reference to changes in general transport costs (GTC). The findings highlight that, notwithstanding a sizeable shift in relative convenience among alternative modes as measured by GTC, commuters and especially car drivers showed resistance to adapting to the big event.
\end{abstract}

\section{Introduction}

Public policy on car use regulation usually relies on both economic incentives (fuel taxes, subsidised public transport, parking fees) and command and control policies (limited traffic zones, car emission controls). However, the efficacy of these measures has proven to be much more limited than expected, as the reaction of car use to these public policies is - as a general finding - very low.

This limited reaction to economic stimuli can be explained by a behavioural approach, which challenges the utility maximization principle by stressing the relevance of heuristics and cognitive biases in decision-making processes. These factors appear particularly important in transport-related decision-making, where traveller identities and habits may add additional issues (Van de Kaa, 2010). Several natural and laboratory economic experiments (Innocenti et al., 2013) have recently added empirical evidence to the idea that a fully rational approach cannot be taken for granted when dealing with travel mode choices. It is evident that heuristics, identity preferences and cognitive biases must be carefully considered when designing public policies, since disregarding these components of agents' decision-making processes leads to policy ineffectiveness and public resource waste (Sustein, 2002).

In this paper, we take advantage of an event that took place in
Florence in September 2013 and required the adoption of special transport arrangements for a whole week. During this special week, the city of Florence experienced: a) a massive enlargement of the pedestrian and limited traffic areas in the city centre; b) an increase in the local public transport supply (both local trains and buses were involved); and c) an information campaign which also included moral suasion towards public transport, walking and cycling travel modes. Although all these alterations led to a remarkable modification in the relative costs of public/private transport (GTCs), commuter behaviour, and in particular their transport mode choices, did not change as much as the modification in GTCs might suggest, showing that routine identity preferences and biases are as important as the traditional drivers of behaviour. Our analysis is conducted by means of a survey of more than 800 commuters working in the area affected by the event. The estimation results contribute to highlighting the main drivers of transport mode changes and, above all, hint at a reluctance to short-term change on the part of car users and the importance of information and attitude toward risk.

After a brief review of the literature analysing behavioural models and natural experiments (Section 2), we describe the big event that made the research possible and the related transport arrangements experienced by the population (Section 3). The data and methodology are presented in Section 4 and the estimation results are discussed in

\footnotetext{
We thank Leonardo Piccini for his help with GTC analysis.

* Corresponding author.

E-mail addresses: patrizia.lattarulo@irpet.it (P. Lattarulo), vmasucci@luiss.it (V. Masucci), mariagrazia.pazienza@unifi.it (M.G. Pazienza).
} 
Sections 5 and 6. Section 7 concludes.

\section{Literature review and research questions}

The traditional rational model considers travel-related choices (transport mode, routes, timing) as an application of the optimising assumption: choices are made with the aim of maximising individual utility, subject to budget, time and comfort constraints. In particular, rational choices are assumed to be made after a mental process that includes assessing a number of options and evaluating risk. In addition, they are applied to very heterogeneous situations, including both important investment decisions (buying a bus season ticket or a new car) and routine situations (commuting). In this approach, agents correctly process all the available information and are not affected by cognitive biases. ${ }^{1}$

In contrast, several behavioural studies show that agents are boundedly-rational, use choice heuristics and are affected by perceptual and cognitive biases (Kahneman and Tversky, 1973). Following Kahneman and Tversky's intuition of a dualistic decision process (a first quick automatic and unconscious system, and a second slow rational one), several empirical analyses have shown how relevant the first system is in travel choices, especially when individuals face repeated circumstances (Starmer, 2000). ${ }^{2}$

Behavioural models usually consider several factors which can alter agents' decision-making processes and are related to their perceptions of alternatives and their evaluation and judgment processes. In the behavioural framework, preferences are not stable and context-independent. On the contrary, perceptions of attributes are strongly context- and reference-dependent and may be easily influenced by carefully chosen framing.

Regarding travel mode choice, the behavioural literature mainly focuses on three main areas: information processing and learning; the impact of the status quo or reference points on travellers' decisions; and the roles of risk attitude and weighted probabilities. ${ }^{3}$

In particular, when considering alternative travel modes, empirical and laboratory evidence shows that real choices are affected by several cognitive biases which undermine rationality. Since the seventies a broad strand of literature has stressed the very low cross-elasticity among transport modes, with part of the population able to be considered 'heavily committed' car users. The high preference for cars that characterises many countries cannot be explained by looking at the traditional economic variables (costs and times) as cars are generally perceived as a means of travel giving status, a sense of comfort, control and freedom (Steg, 2005; Steg et al., 2001). Following Steg's contributions, recent psychological and sociological literature on transport has stressed the importance of the travel mode in defining consumer identity, and has investigated the relationship between 'transport identity' (as driver, pedestrian, biker ...) and economic choices (Murtagh et al., 2010). Undervaluation of the costs associated with car use - direct, indirect and external - is a combined effect of myopia and biases in information processing: costs are frequently under-evaluated because they are only partially paid simultaneously with car use. On the other hand, heuristics, habits and subjective weighted probabilities distort travel time expectations.

Moreover, travellers' rationality seems to be negatively affected by

\footnotetext{
${ }^{1}$ As Goodwin (1977) pointed out, “... however, the traveller does not carefully and deliberately calculate anew each morning whether to go to work by car or bus. Such deliberation is likely to occur only occasionally, probably in response to some large change in the situation." p.95.

${ }^{2}$ For a review of the implications of dual systems in economic modelling, see Alós-Ferrer and Strack (2014).

${ }^{3}$ For a review of applications of behavioural concepts to transport, see Garcia-Sierra et al. (2015). For a meta-analysis of models considering the interaction among cognitive mechanisms and travel behaviour, see Hoffman et al. (2017).
}

repeated choices (Garling, 1998). Mahmassani's (1996) survey on the behaviour of commuters reveals that they are mainly guided by heuristic rules, whereas Verplanken et al. (1994) show that if habitual behaviour increases in strength, mental and cognitive efforts are reduced to a minimum and additional information is scrutinised less accurately. Analysing commuter choices raises several interesting issues. ${ }^{4}$ On the one hand, commuting is associated with a low satisfaction level and behavioural anomalies (such as limited willpower and loss aversion) may play an important role in explaining why commuters are trapped in an inferior status quo (Frey and Stutzer, 2004). Indeed, commuting can be described as a routine which is characterised by patterns, recurrence and social interaction. Interestingly, according to the literature, routines can either be characterised by 'mindlessness' - very similarly to Verplanken et al. (1994) point - or by 'effortful accomplishment.' To obtain a change in routine, salient stimuli and appropriate feedback can be applied, but they can only be effective if the role of the status quo as a reference point is properly taken into account. ${ }^{5}$ This leads to the problem of properly identifying the reference point, which is a multifaceted concept and not necessarily coincident with commuters' actual experiences. Only after taking into account its determinants and all the biases influencing travellers' choices is it possible to design an effective transport policy promoting more sustainable travel mode choices (Schneider, 2013).

Commuting choices can also be affected by reinforcement heuristics, a sort of automatic decision-making process that relies on past performances and leads to a tendency to automatically repeat decisions that worked in the past (see Alós-Ferrer and Strack, 2014). In other words, commuting can be seen as an example of boundedly-rational behaviour. The possibility of inducing a change in this framework is still an open question: some researchers find that habits can be broken (Fujii and Kitamura, 2003), whereas others find them more difficult to break (Garvill et al., 2003).

Gärling and Axhausen (2003) emphasise that habit - or sticking to the status quo - in travel behaviour implies a choice that is non-deliberate and therefore difficult to influence with economic incentives and rational arguments (e.g. increased relative costs), since the person making the choice tends to discount relevant information. When breaking a habit, the search cost for an alternative can be perceived as too high and the expected gains associated with new alternatives too uncertain. Therefore, travellers use past routines to find easier and less risky solutions, especially if they are constrained by time, budgets or family commitments.

One strand of literature focuses on the impact of big events and disruptive episodes on mobility choices. Friedman et al. (2001) studied how traffic changed in Atlanta during the 1996 Summer Olympic Games, and Parkes et al. (2016) focused on the London Games, analysing the process of behavioural changes during the event and their lasting consequences. This literature generally finds that travellers have the flexibility to adapt to new circumstances, but there is a clear link between previous travel behaviour and the type and intensity of travel changes (Parkes et al., 2016; Fujii and Kitamura, 2003; Fujii et al., 2001).

Our research questions arise from considering different literature approaches. ${ }^{6}$ Rational models predict that travel mode choice is a function of costs, time and other factors such as comfort. Behavioural models highlight the role of habits and biases in processing information and, when commuting is the relevant framework, habits and reinforcement heuristics may become dominant due to the sole activation

\footnotetext{
${ }^{4}$ Indeed, Garcia-Sierra et al. (2015) distinguish between long-term choices (location, buying a car) and short-term choices (such as time and mode choices). Commuting involves many repeated short-term choices.

${ }^{5}$ For a review of the routine literature, see Becker (2004).

6 "Although for clarity 'habit' and 'rational' styles of behaviour are counterposed, this is not meant to imply that habit is necessarily bad" Goodwin (1977).
} 
of Kahneman and Tversky's 'system 1.'

In this paper, the focus is on travel mode changes after a radical though temporary - reorganization of road and public transport networks due to a big sports event lasting one week. Because of the characteristics of the event - a cycling world championship - car use was strongly discouraged with bans on car and motorbike use in vast areas and by removing ordinary parking spaces without replacing them. On the other hand, public transport was increased and incentivized. Considering these changes, it was very easy to realize that car travel costs and times would show a spike during the week of the sports event. Pushed by these monetary and time incentives, a rational car user should have changed his ordinary travel mode to cycling, walking or using public transport, in accordance with comparative Generalized Transport Costs (GTCs). Our empirical analysis therefore aims to assess whether cost and time can be considered the most relevant variables in the decision to change travel mode during a big event or, on the contrary, there is evidence of a contribution of different decision-making processes that need to be investigated. Although the occurrence of a big or disruptive event can be considered very important in inducing lasting behaviour change (Verplanken and Wood, 2006, Fujii and Kitamura, 2003; Fijii et al., 2001), in this paper we cannot directly investigate the long-term consequences of observed changes.

\section{A big sports event as an opportunity to analyse individual behaviours}

The organization of the Road World cycling championships in Florence in September 2013 created a unique opportunity to test citizens' reactions to a totally different mobility system to the ordinary one.

Florence is a medium-sized Italian city $(350,000$ inhabitants). Notwithstanding its relatively good supply of public transport, mobility is characterised by a strong modal imbalance towards car use $(67 \%$ of commuters use the car), leading to high levels of congestion, accidents and pollution (Lattarulo, 2003; Legambiente, 2007). The historical structure of the city and the large urban sprawl ${ }^{7}$ creates a bias toward private mobility, which exacerbates the aforementioned difficulties.

The organization of the big event - to which many visitors were expected - affected most of the urban area for a full week, requiring a set of regulatory policies and an extensive information campaign.

The policy action taken in the course of the event concerned:

a) many road closures in the historical centre and in most of the urban area;

b) an increased supply of local public transport services and regional trains;

c) an information campaign discouraging people from accessing the city by car.

\section{a) Enlargement of limited traffic zones}

The restrictions concerned a large section of the city's built-up area for the duration of the event: the use of private vehicles was hindered by the closure of various roads and by the creation of large no-parking areas.

Fig. 1 shows the cycling championship racetrack.

The area affected by the event represented a large part of the municipality area - thus doubling the size of the ordinary daytime Limited Traffic Zone (Table 1).

\section{b) Support policies: an increased supply of public transport and emergency services}

\footnotetext{
${ }^{7}$ According to the OECD Metropolitan Areas Database, Florence has one of the highest urban sprawl indexes in Italy.
}

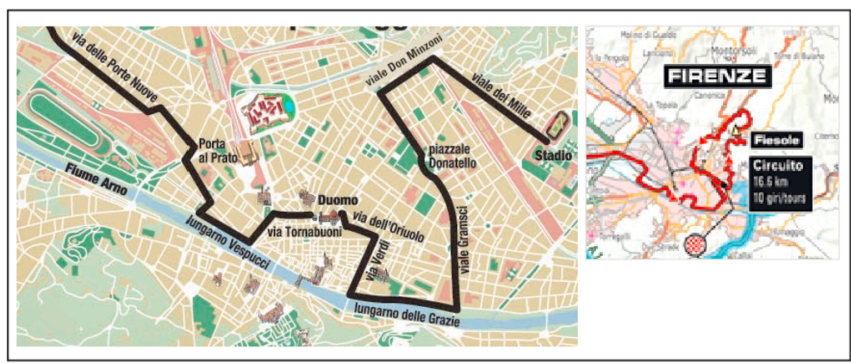

Fig. 1. The area of Florence affected by the cycling world championship on 25th September 2013.

Table 1

Comparison between the Sports Event area, the daily Limited Traffic Zone and the whole Florence municipality.

\begin{tabular}{lrrr}
\hline & Employment & Population & \multicolumn{1}{c}{ Area (m²) } \\
\hline Sports Event Area & 15,225 & 34,470 & $5,441,440$ \\
Daily Limited Traffic Zone & 36,890 & 37,688 & $4,985,124$ \\
Florence municipality & 156,273 & 358,079 & $102,320,000$ \\
\hline
\end{tabular}

Source: our estimation using Istat data.

Supplementary bus routes were put into operation to ease the movement of residents and visitors. The railway service was enhanced with extra services in the region, in particular with trains taking bicycles on board. Moreover, inter-modality was incentivized with special combined rail-bus tickets.

\section{c) Information and prevention campaign}

The extensive information campaign - which started four months beforehand and continued throughout the event - used all kinds of dissemination channels (the press, television, brochures, websites, apps). The stream of information was non-stop throughout the event and provided details of the new mobility organization and service statuses and it always warned not to use the car. ${ }^{8}$ Indeed, the information flow was designed to both enhance the city's engagement with the event and at the same time to create apprehension about potential traffic jams and travel chaos (a so-called 'big scare') in order to induce a change in travel mode (Jones et al., 2015).

\section{Collecting data: taking advantage of the big event}

As previously explained, the preparation for the 2013 Road World bike championship in Florence forced local administrators to completely change the mobility network during the event. The championship can therefore be considered a 'big event' and we take advantage of the episode to analyse travel behaviour in a 'quasi-natural experiment.' With the same premises, Friedman et al. (2001) studied how traffic changes in Atlanta during the 1996 Summer Olympic Games affected air quality and childhood asthma by comparing the 17 days of the Olympic Games to a baseline period. As is widely known, a natural experiment is a study of the effect of an independent variable which has not been planned or manipulated by the researchers (and is therefore 'natural') on a dependent variable. Taking advantage of the natural experiment framework, we use a transport modelling approach to analyse the drivers behind the decision of whether to change transport behaviour or not. Our empirical data rely on a specific questionnaire

\footnotetext{
${ }^{8}$ The information campaign used both traditional channels (local TV and newspapers) and online media (web sites and social) to reach the largest part of the population in the Tuscan region. Announcements online were updated in real time and announcements on TV and radio where diffused every few hours.
} 
which collected information on everyday commuter travel choices on a specific date during the event week (Wednesday 25 September 2013). ${ }^{9}$

The survey collected personal and transport-related information from a total of 883 interviewed workers employed by public and private enterprises in the Florence area. ${ }^{10}$ The questionnaire covered the following issues ${ }^{11}$

- the respondent's demographic characteristics (age, gender);

- the respondent's travel-to-work characteristics (origin/destination inside Florence, incoming and outgoing times and usual transport mode $)^{12}$

- needs to accomplish tasks for the family during the commute (sports, child care);

- transport mode choice and accomplishment of the activity routine on 25 September 2013;

- access to information provided by local authorities about the new mobility plan (TV channel, newspaper, web);

- attitudes to risk, tested by means of a hypothetical question about crossing the road under risky conditions. ${ }^{13}$

Table 2 presents descriptive statistics of the observations collected in the survey.

Although this sample of employees - aged between 18 and 65 and mainly male - cannot be considered representative of the total population in the same age span, it is interesting to note (Table 3) that several characteristics are very similar to those provided by the 2011 census for labour-related commuters. ${ }^{14}$

Regarding the habitual transport mode, Fig. 2 shows the prominent role of cars, which were chosen by nearly $50 \%$ of the sample, and by $54 \%$ of female respondents.

\section{How much did commuters react to the big event traffic limitation?}

With all the limitations previously discussed, survey data can give important information on the behavioural reaction of the subjects during a big event and provide an estimate of the propensity to change travel mode. The big event modified the mobility pattern, causing a shift in the costs and times of all means of transport, in both absolute and relative terms.

Considering the vast enlargement of the pedestrian zone, the street closures, the diverted routes and parking bans, private cars were deeply discouraged and were more affected by the event than other transport modes. However, a change from cars to other transport modes depends on relative costs (measured by GTCs) and on the actual availability of

\footnotetext{
${ }^{9}$ Another example of event-based behavioural change analysis through questionnaires can be found in Rose and Marfurt (2007).

${ }^{10}$ The survey was completed via a website and with the support of firm mobility managers. Since 1998, large Italian companies have had to nominate a mobility manager with the aim of reducing commuting time and of promoting a collective transport network.

${ }^{11}$ For the use of questionnaires in the analysis of mobility behaviour, and particularly driving behaviour, see Lajunen and Summala (2003).

${ }^{12}$ To this end, we built dummy variables to better identify the origin and destination (O/D) of the journey with respect to the Florence municipality to consider differences in transport alternatives for the different journeys, as within the urban area there are more alternatives than for journeys including non-urban areas.

${ }^{13}$ The question on potential attitudes towards a risky road crossing provided the following alternatives: going to the nearest traffic light (risk averse); crossing the road as quickly as possible (risk lover); crossing the road carefully (risk neutral). See Barton and Morrongiello (2011) and Pawlowski et al. (2008). On the issue of risk aversion/propensity in driving behaviour, also see Cestac et al. (2011).

${ }^{14}$ Italian Census data are provided by Istat, the Italian National Institute of Statistics.
}

Table 2

Descriptive statistics of the dataset.

\begin{tabular}{lll}
\hline Variable & $\mathrm{N}$ & Average \\
\hline Age & 883 & \\
18-25 years (\%) & & 5.4 \\
25-50 years (\%) & & 65.2 \\
$\quad$ Over 50 years (\%) & 831 & 29.4 \\
Number of dependent children & 874 & 1.17 \\
Gender (\% male) & 858 & 65.9 \\
Destination outside Florence (\%) & 856 & 13.9 \\
Destination within Florence (\%) & 883 & 86.1 \\
O/D inside Florence (\%) & 883 & 44.6 \\
Respondents with activities along the way (\%) & 863 & 18.1 \\
Average distance (km) & 719 & 37.2 \\
Average travel time (mins.) & 848 & \\
Risk attitude & & 4.2 \\
$\quad$ Risk lover (\%) & & 58.8 \\
Risk neutral (\%) & & 36.9 \\
$\quad$ Risk averse (\%) & &
\end{tabular}

Table 3

Comparison between census data and the dataset.

\begin{tabular}{lll}
\hline & Census 2011 data & Survey \\
\hline Transport mode: & & \\
Car & 46.6 & 47.2 \\
Motorcycle & 18.1 & 23.0 \\
Bus, tram, train & 17.5 & 21.8 \\
Cycling & 5.6 & 5.9 \\
Walking & 8.0 & 2.0 \\
Gender (\% Male) & 52.8 & 65.9 \\
O/D inside Florence & 48.7 & 44.6 \\
Destination outside Florence & 13.6 & 13.9 \\
Destination within Florence & 86.4 & 86.1 \\
\hline
\end{tabular}

Source: Istat, 2011 and Survey.

alternatives. Indeed, public transport services - buses and trains - can be considered widely available in the Florentine region and the city centre is easily crossed on foot and by cycling.

The Generalized Transport Cost (GTC) of car use is estimated (Table 4) by computing the distances and costs ${ }^{15}$ between 9 centroids ( 5 districts in the city and 4 points on the main ways into the town) before and during the event. To consider the different availability of alternative modes, we separately consider the flow within the city centre (O/D Florence) and all other flows.

The synthetic GTC matrix for cars has three components: time opportunity cost (using the average hourly wage, VoT), the operating cost per kilometre (a value in euro/ $\mathrm{km}$, Cost-Km) and road tolls, if relevant, in the O/D flows. Therefore, these estimations disregard other potentially relevant monetary and time costs, such as additional parking costs, uncertainty and congestion costs. The three components are shown in the following formula:

$\mathrm{GTC}_{\mathrm{ij}}=\left(\right.$ Time $\left._{\mathrm{ij}}{ }^{*} \mathrm{VoT}\right)+\left(\right.$ Dist $_{\mathrm{ij}}{ }^{*}$ Costkm $)+$ Tolls $_{\mathrm{ij}}$

Where $\mathrm{i}$ represents different origin and destination flows (O/D) and $j$ the 9 centroids.

Table 4 shows the different components of the GTCs. Commuting time appears as the most relevant variable (10 and 7.3 euros) and the one most affected during the event $(+30.1 \%$ for O/D within the city borders). On the contrary, operating costs within the city borders can be considered substantially unchanged, as the new routes to avoid the race did not add relevant distance. The diverted car flow on motorways was negligible.

GTC estimations show an average value of 17 euros for ordinary

\footnotetext{
${ }^{15}$ We consider both direct financial costs and time spent converted into monetary terms.
} 


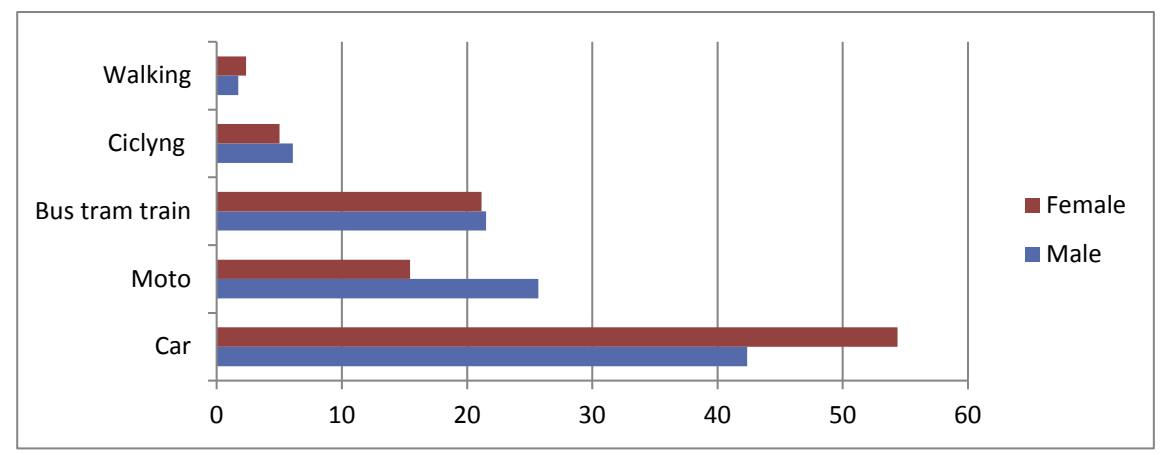

Fig. 2. Habitual travel mode choice by gender (\%).

Table 4

Components of Generalized Transport Cost (GTC) change for private cars. Euro and percentage differences.

\begin{tabular}{|c|c|c|c|c|c|c|c|c|}
\hline \multicolumn{3}{|c|}{ TIME Time $\mathrm{x}$ labour cost } & \multicolumn{3}{|c|}{ DISTANCE Operating cost $\mathrm{x}$ Cost $/ \mathrm{km}$} & \multicolumn{3}{|l|}{ MOTORWAY Toll } \\
\hline & All O/D & O/D Florence & & All O/D & O/D Florence & & All O/D & O/D Florence \\
\hline Ordinary & 10,0 & 7,3 & Ordinary & 6,6 & 2,5 & Ordinary & 0,4 & 0 \\
\hline During the event & 12,0 & 9,5 & During the event & 8,0 & 2,5 & During the event & 0,4 & 0 \\
\hline Var\% & 20,0 & 30,1 & Var\% & 20,8 & 0,0 & Var\% & 0 & 0 \\
\hline
\end{tabular}

Table 5

Change in Generalized Transport Cost (GTC) for private cars. Euro and percentage differences.

\begin{tabular}{|c|c|c|}
\hline & Commuting through Florence (All Origins and Destinations) & Commuting through Florence (O/D only within city borders) \\
\hline Ordinary GTC & 17.0 & 9.8 \\
\hline GTC during the big event & 20.4 & 12.3 \\
\hline \% Difference & $20.0 \%$ & $25.9 \%$ \\
\hline
\end{tabular}

commuting by car through Florence (considering all the possible origin and destination points) and a lower value -9.8 euros - for the average journey within the city area (Table 5 ). ${ }^{16}$ On the specific day of the survey, an overall extra cost of $20 \%$ is considered (from 17 to 20.4 euros), whereas $25 \%$ extra cost is added for commuting within the city borders (from 9.8 to 12.3 euros), due to additional distances (to avoid the race area) and tolls.

Travelling by car also involved increased uncertainty because the probability distribution of traffic jams, which commuters estimate using their experience, varied, making delays completely unpredictable. Moreover, the information campaign tried to persuade people not to use the car and tried to build a sort of social norm to sustain the sports event, including refraining from making normal mobility choices. ${ }^{17}$

While the use of the car was deeply discouraged, bus and railways

\footnotetext{
${ }^{16}$ To estimate the GTC for cars, regional and census data on commuting flows and geo-referenced maps are used. For ordinary commuting costs (distances and times) by car, 9 centroids as O/D are considered, using Google map API for time and distance calculations, to build cost and time matrices. The synthetic GTC for the car matrix uses a time opportunity cost (using the average hourly wage in Tuscany) equal to 20 euros/hour, an operating cost per kilometre of 0.4 euro/km (Automobile Club Italia tables, CostKm) and the actual road tolls, if relevant, in the O/D flows.During the event, commuters were forced to change their usual itinerary to avoid the race area, so times and distances changed. The new generalized transport costs and matrices are estimated accordingly.The final results are computed as the differences between ordinary GTCs and GTCs during the event, using commuter flows on census data as weights: $\triangle \mathrm{GTCs} \&$ $\# \times 202 F ;=\& \# x 202 F ; \Sigma i j((G T C$ ij ordinary - GTC $i j$ during the event $) * F l o w i j) / \Sigma i j$ Flowij.

${ }^{17}$ Building a social norm to engage citizens in the big experience can also improve well-being during the event. See Dolan et al. (2017) on the London Olympics.
}

services were improved in order to partially compensate inconveniences and to limit hardship to commuters. Moreover, inter-modality was incentivized with special combined rail-bus tickets. All these measures were introduced to boost people's and tourists' use of public services instead of private cars. Finally, we can consider that other transport modes like cycling and walking should have been less affected by the event, because of the distances concerned and the permeability of the street and lane closures.

Because of this altered mobility framework, we expect a behavioural reaction from the majority of commuters, and in particular from car users. One possible reaction - an over-reaction - is to give up all daily activities, including going to work, and to try to use the week for other purposes, such as holidays, attending the sports event or accomplishing non-work activities. The expected behaviour is not so drastic: an adjustment of the daily routine, changing travel times or transport mode in response to the change in expected journey times and costs (GTCs), would be the most likely outcome. Finally, subjects may have carried on with their usual activities without any change because they were only marginally affected by the big event or because they were stuck in their habits. The chart below schematizes the different behavioural options.

The survey results show that $8 \%$ of commuters gave up their daily activities (case b.1 in Fig. 3), whereas the majority of them stuck to their habitual transport modes and travel times $(60 \%) .{ }^{18}$ On average, a minority modified their habitual behaviour: $21 \%$ changed times but only $11 \%$ changed transport mode (b.2 and b.3 in Fig. 3). Moreover, we cannot find any noticeable difference between changes made by car users and other close alternatives (e.g. bus riders), especially in terms of

\footnotetext{
${ }^{18}$ Parkes et al. (2016) show that more than $60 \%$ of their subjects made some change during the London Games in 2012, but only $11 \%$ changed transport mode.
} 


\begin{tabular}{|c|c|c|}
\hline No change (Business as Usual) & a) $\rightarrow$ & Same activities, transport mode and travel time \\
\hline Behavioural change & b) $\underset{\searrow}{\longrightarrow}$ & $\begin{array}{l}\text { b.1) No work activities, no commuting to work } \\
\text { b.2) Change of travel time } \\
\text { b.3) Change of transport mode }\end{array}$ \\
\hline
\end{tabular}

*Those who change both transport mode and travel time are assigned to b.3

Fig. 3. Available transport choices during the sports event*

Those who change both transport mode and travel time are assigned to b.3.

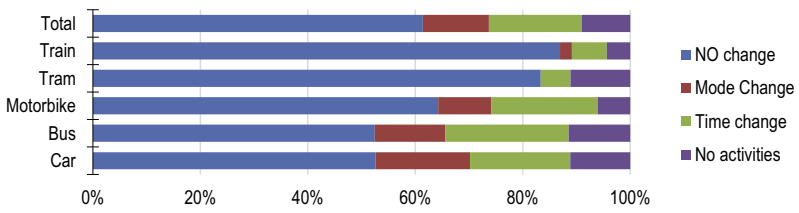

Fig. 4. Behaviour during the big event by habitual transport mode. Cycling and walking choices omitted. mobility framework, changes in GTCs and in transport mode choices are considered by comparing the situation before and during the event. In more detail, the ratio of the percentage of car users changing travel mode ( $\Delta \mathrm{D}$ (cars)) to the percentage change in car GTCs ( $\Delta \mathrm{GTC}$ (cars)) allows an estimation of the own cost elasticity during the event $(\mathcal{E}$ (cars)). This is shown in Table 6.

The table shows that $18 \%$ of car commuters changed their transport mode after a $20 \%$ increase in their GTC, resulting in an elasticity of

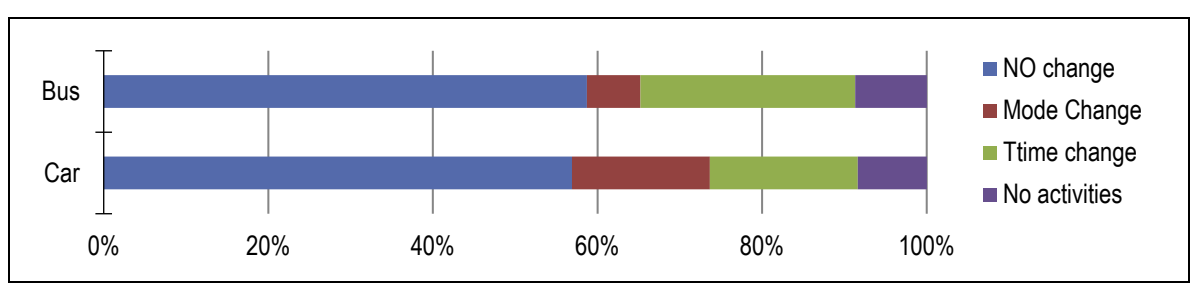

Fig. 5. Behaviour during the big event by habitual transport mode: selected subjects with habitual working activities during the event, travelling within the city limits and without tasks to accomplish during the commute (305 subjects).

switching means of transport, so only fewer than $18 \%$ of car users left the car at home to commute during the event (Fig. 4).

To sum up, among the $60 \%$ of the employees who did not change their behaviour during the big sports event, we can identify different segments: those not greatly affected by the relative cost and journey time changes (such as people who reach their workplace by train or by walking or cycling), those forced to use their habitual transport mode because of the daily activities they need to accomplish (e.g. driving children to school) and those who stuck to their habits even though their habitual travel mode was deeply penalized by the event-related policies. Indeed, in order to investigate this point, if we focus on those travelling within the city limits and with no tasks to accomplish during the work-to-home journey (Fig. 5), we would expect a greater elasticity of transport behaviour (in terms of mode and time) in response to the change in relative times and costs, especially with regard to car users. This is because commuters not constrained by particular tasks to accomplish may easily consider a change in travel behaviour. ${ }^{19}$

Contrary to this expectation, Fig. 5 shows that more than $57 \%$ of the car users in this sub-sample stuck to their habitual transport behaviour and did not change either transport mode or travel times. This percentage is very close to that for bus users, for whom, on the contrary, there was an improvement in transport conditions.

Automatic traffic counting in the Florence urban area confirms our results. The automatic system - using sensors and cameras - monitored vehicle flows on main roads on different dates before $(16,17,18,19$ September) and during the event (23, 24, 25, 26 September). Fig. 6 shows an average traffic flow reduction of $16 \%$ during the event. This difference is the result of lower private mobility (work- and non-workrelated mobility) induced by the event and the additional mobility due to tourists and event-related activities.

In order to estimate car drivers' propensity to adapt to the new

\footnotetext{
${ }^{19}$ For an estimation of the more inelastic private transport demand for families with children in Italy, see Fiorio and Percoco (2007).
}

- 0.9. Focusing on car commuters within the city borders, a smaller elasticity of-0.7 emerges, a rather inelastic value (Wardman, 2014). This evidence, which is unexpected because of the greater transport opportunities in city centres, is consistent with some previous findings in the literature (Litman, 2017). ${ }^{20}$

The empirical literature on transport elasticity contains heterogeneous results depending on transport mode (car, bus, train ...), motivation (commuting, leisure, business ...), urban vs. extra-urban $\mathrm{O} / \mathrm{D}$, distance and income. ${ }^{21}$ Our findings are, generally speaking, consistent with the literature but bring new evidence by means of an original case study. We interpret the results as a kind of evidence of inelastic demand, considering the out-of-the-ordinary context, the short-term analysis and the policy against car use and in favour of the use of alternative transport modes.

\section{Drivers of behavioural change}

The main goal of this paper is to investigate the propensity of individuals to change transport mode when the general mobility framework changes. To better assess the potential bias in the form of resistance to change, ordinary mobility behaviours were first studied using survey data to check the correspondence with the existing international literature. The findings of the preliminary analysis of individual attitudes in routine transport choices - not shown in the paper - confirm that age, gender, risk attitude and daily household tasks to

\footnotetext{
${ }^{20}$ According to these findings, the risk of road disruption and congestion can provide a stronger incentive towards alternative transport modes and adaptation on extra-urban flows.

${ }^{21}$ Litman (2017) underlines that these GTCs should be calculated for each specific community, looking at local travel behaviour and using survey data. According to his review of the literature, car user GTC elasticities range between -0.5 and -2 , considering short-vs long-run analysis and comparing effects after two or ten years. None of this literature examines GTC elasticity in the context of a 'one week event'.
} 


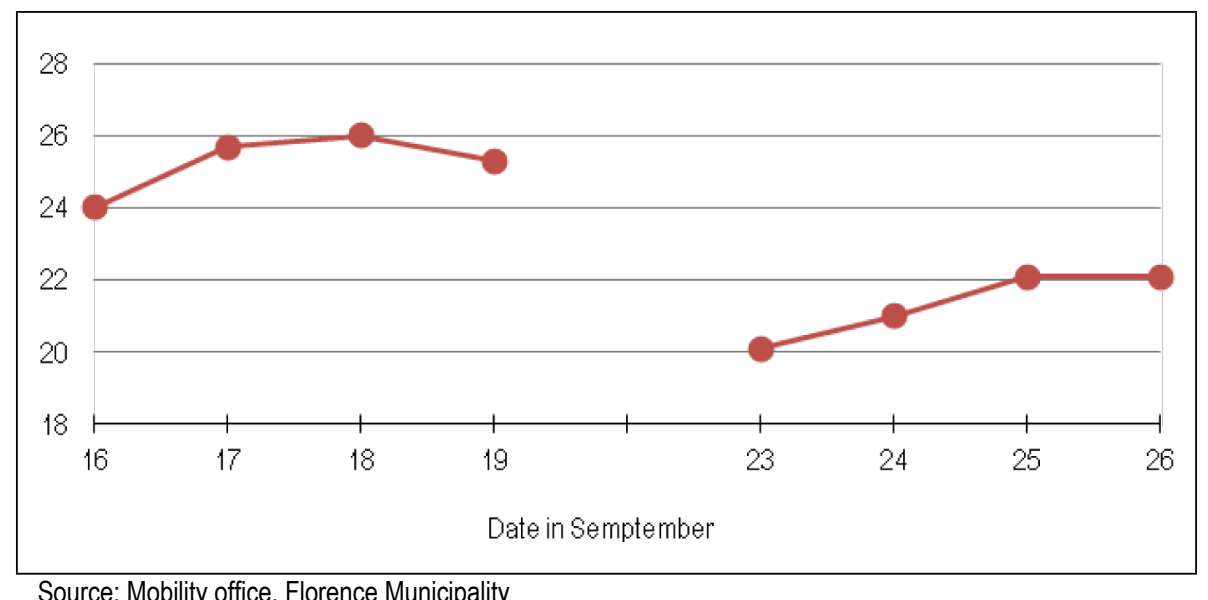

Fig. 6. Car flows preceding and during the event (thousands)

Source: Mobility office, Florence Municipality.

Table 6

Own cost propensity to change travel mode for car users during the sports event.

\begin{tabular}{lll}
\hline $\mathcal{E}$ (car) & $\Delta \mathrm{D}(\mathrm{car}) / \Delta \mathrm{GTC}(\mathrm{car})$ & \\
\hline Total Commuters $\mathcal{E}$ (car) & $\Delta \mathrm{D}(\mathrm{car})$ & $-18 \%$ \\
& $\Delta \mathrm{GTC}(\mathrm{car})$ & $20 \%$ \\
& & $-20 \%$ \\
Commuters within Florence districts $\mathcal{E}(\mathrm{car})$ & $26 \%$ \\
& $\Delta \mathrm{D}(\mathrm{car})$ & \\
& $\Delta \mathrm{GTC}(\mathrm{car})$ & \\
\hline
\end{tabular}

accomplish are among the key drivers. ${ }^{22}$

To test the effect of individual characteristics on transport choice responses during the Road World cycling championships, we use a binomial logit model related to the diagram shown in Fig. 3. The dependent variable is constructed to take the behavioural choice values 'change' (case b) and 'no change' (case a). The independent variables are the information collected from the questionnaire regarding: age group (age), ${ }^{23}$ the presence of dependent children (children), gender (gender), activities along the way (activities), home-to-work distance (distance, in $\mathrm{km}$ ), home-to-work travel time (time, in minutes) and attitude towards risk (risk-averse/neutral/lover). Moreover, for the sake of completeness and as a further robustness check, we also run a linear probability model (List et al., 2001).

The specifications of the logistic regression and linear models are as follows:

$$
\begin{aligned}
& \ln \left(\frac{P(\text { change })}{P(\text { no change })}\right)= c+\pi D_{i}(\text { radioTv })+\mu D_{i}(\text { destination Florence }) \\
&+\alpha D_{i}(\text { children })+\gamma D_{i}(\text { gender })+\delta D_{i}(\text { car }) x \text { time } \\
& \\
&+\eta D_{i}(\text { car })+\vartheta D_{i}(\text { age } 18 \text { to } 25)+\lambda D_{i}(\text { age over } 50) \\
&+\xi \text { distance }_{i}+\varpi \text { time } e_{i}+\varphi D_{i}(\text { risk lover }) \\
&+\tau D_{i}(\text { risk adverse })+\epsilon_{i}
\end{aligned}
$$

\footnotetext{
${ }^{22}$ We employ a multinomial logit model whose dependent variable is the habitual transport mode (car, motorbike, bus, train, bicycle) as collected by the questionnaire. It is worth noting that a higher propensity to use the car for daily commuting can be found in subjects coming into the city from other areas, in men in the 25-50 age group and among those more inclined to take risks. These results are consistent with the wide literature on the issue and offer further evidence of gender differences and related propensities in driving behaviour (Özkan and Lajunen, 2006).

${ }^{23}$ Three age groups are considered: $18-25,25-50$ and over 50.
}

$$
\begin{aligned}
y_{i}= & c+\pi D_{i}(\text { radioTv })+\mu D_{i}(\text { destination Florence })+\alpha D_{i}(\text { children }) \\
& +\gamma D_{i}(\text { gender })+\delta D_{i}(\text { car }) x \text { time }_{i}+\eta D_{i}(\text { car })+\vartheta D_{i}(\text { age } 18 \text { to } 25) \\
& +\lambda D_{i}(\text { age over } 50)+\xi \text { distance }_{i}+\varpi t i m e+\varphi D_{i}(\text { risk lover }) \\
& +\tau D_{i}(\text { risk adverse })+\epsilon_{i}
\end{aligned}
$$

Two more variables are included in the model: the informationgathering channel (radioTv) and the interaction between car driving and travel time. ${ }^{24}$ The latter is important because in the specific urban area there is a minimum time threshold below which car use is never convenient. $^{25}$

The dummy in the logit model takes value 1 if the employee changed his behaviour (no activities, changing time, changing mode, 313 observations) and 0 otherwise (499 observations). See Table 7.

Table 8 presents the coefficients of the linear probability model (LPM, column 1), the logit model (col.2) and the marginal effects computed through logit estimation (col. 3). It is worth stressing that the estimation results - comparing the coefficients of the LPM to the marginal effects of the logit - are almost identical and this might be interpreted as a sign of robustness. ${ }^{26}$ Both the F-test and the LR $\chi^{2}$ test indicate that the regressors are jointly significant in explaining the probability of behaviour change during the sports event. In addition, the values of $R^{2}$ and pseudo $R^{2}$ for the binary model can be regarded as satisfactory.

The estimation results show that individual characteristics are relevant to the subject's willingness to adapt to the event and change habit, as was found for their role in explaining the habitual transport mode. The existence of dependent children in the family, male gender, a young age and a propensity for risk are relevant factors weakening the motivation to adapt, as is evidenced by the marginal effect values. The presence of dependent children entails a $13 \%$ reduction in the probability of changing mobility habit; similarly, being male is associated with a $14 \%$ lower probability of change as compared to female gender; and an age between 18 and 25 decreases the probability by $31 \%$. Regarding the characteristics of the route, the first piece of evidence is that journeys into the town were those most affected by the Road World championships and they necessarily had to be adapted (incoming commuters have a higher probability of a change than others: $+22 \%$ ).

\footnotetext{
${ }^{24}$ As Avineri and Ben Elia (2015) discuss, information has been shown to be important in travel behaviour and it influences cognitive bias and attention.

${ }^{25}$ In addition to the car\&\#x202F; $\times \& \# x 202 F$;time relation, all the other possible interactions with car choice are tested in the model (assuming the likelihood of other common particularities among this group of respondents), but none of them are significant.

${ }^{26}$ See Horrace and Oaxaca (2006) for details.
} 
Table 7

Behavioural reaction during the sports event.

\begin{tabular}{lll}
\hline Change of behaviour & N. & Percentage \\
\hline No & 499 & 61.45 \\
Yes & 313 & 38.55 \\
TOTAL & 812 & 100.00 \\
\hline
\end{tabular}

travel habits as a result of the event restrictions and the changed framework.

As sticking to car use is the most interesting result for traffic management, we focus on the group of car drivers (almost half of the sample). As shown above (Figs. 4 and 5), car users did not show the expected adjustment of behaviour after the changes to their journey time and cost, even when only the sub-sample of those travelling within

Table 8

Effects of personal characteristics on behavioural change. OLS (with robust standard errors), logit and marginal effects.

\begin{tabular}{|c|c|c|c|}
\hline Variables & (1) LPM & (2) Logit & (3) Marginal effects \\
\hline \multirow[t]{2}{*}{ Radio TV } & $0.107^{* *}$ & $0.535^{* *}$ & $0.105^{* *}$ \\
\hline & $(0.0471)$ & $(0.241)$ & $(0.0467)$ \\
\hline \multirow[t]{2}{*}{ Destination Florence } & $0.229^{* * *}$ & $1.147^{* *}$ & $0.225^{* *}$ \\
\hline & $(0.0773)$ & $(0.511)$ & $(0.0989)$ \\
\hline \multirow[t]{2}{*}{ Children } & $-0.134 * * *$ & $-0.657^{* * *}$ & $-0.129^{* * *}$ \\
\hline & $(0.0427)$ & $(0.207)$ & $(0.0393)$ \\
\hline \multirow[t]{2}{*}{ Gender (Male) } & $-0.153 * * *$ & $-0.723^{* * *}$ & $-0.142^{* * *}$ \\
\hline & $(0.0420)$ & $(0.197)$ & $(0.0371)$ \\
\hline \multirow[t]{2}{*}{ Car\&\#x202F; ×\&\#x202F;time } & $0.00599 * * *$ & $0.0341^{* * *}$ & $0.00669^{* * *}$ \\
\hline & $(0.00147)$ & $(0.00950)$ & $(0.00180)$ \\
\hline \multirow[t]{2}{*}{ Car } & 0.000391 & -0.141 & -0.0277 \\
\hline & $(0.0713)$ & $(0.372)$ & $(0.0730)$ \\
\hline \multirow[t]{2}{*}{$18-25$ years } & $-0.304 * * *$ & $-1.581^{* * *}$ & $-0.310^{* * *}$ \\
\hline & $(0.0943)$ & $(0.609)$ & $(0.117)$ \\
\hline \multirow{2}{*}{ Over 50 years } & 0.00319 & -0.0114 & -0.00224 \\
\hline & $(0.0405)$ & $(0.207)$ & $(0.0406)$ \\
\hline \multirow[t]{2}{*}{ Distance (avg. km) } & $-0.00670^{* * *}$ & $-0.0390 * * *$ & $-0.00766^{* * *}$ \\
\hline & $(0.00134)$ & $(0.00931)$ & $(0.00174)$ \\
\hline \multirow[t]{2}{*}{ Time (avg. minutes) } & $0.00363^{* * *}$ & $0.0186^{* * *}$ & $0.00366^{* * *}$ \\
\hline & $(0.00124)$ & $(0.00649)$ & $(0.00124)$ \\
\hline \multirow[t]{2}{*}{ Risk lover } & $-0.322^{* * *}$ & $-2.426^{* *}$ & $-0.476^{* *}$ \\
\hline & $(0.0748)$ & $(1.081)$ & $(0.210)$ \\
\hline \multirow[t]{2}{*}{ Risk averse } & 0.0225 & 0.138 & 0.0270 \\
\hline & $(0.0389)$ & $(0.194)$ & $(0.0381)$ \\
\hline \multirow[t]{2}{*}{ Constant } & $0.247 * *$ & $-1.185^{* *}$ & \\
\hline & $(0.101)$ & $(0.585)$ & \\
\hline Observations & 605 & 605 & 605 \\
\hline $\mathrm{F}(12,592)$ & 18.82 & & \\
\hline Prob.\&\#x202F; > \&\#x202F;F & 0 & & \\
\hline $\mathrm{R}^{2}$ & 0.1699 & & \\
\hline Root MSE & 0.44959 & & \\
\hline LR chi2 (12) & & 113.88 & \\
\hline Prob\&\#x202F; > \&\#x202F;chi2 & & 0 & \\
\hline Pseudo $\mathrm{R}^{2}$ & & 0.1407 & \\
\hline Log likelihood\&\#x202F; = \&\#x202F; & & -347.62133 & \\
\hline
\end{tabular}

Notes: robust standard errors in parentheses; *p\&\#x202F; < \&\#x202F;0.1, **p\&\#x202F; < \&\#x202F;0.05, ***p\&\#x202F; < \&\#x202F;0.01.

Commuters travelling long distances tended to avoid a change of transport mode, whereas those with longer journey times were more prone to change. Information channels also played a role: those who got information from local radio and TV channels - which typically produce repeated short news reports and thus magnify the impact - had a higher probability of changing. ${ }^{27}$ Moreover, the people most averse to change were risk lovers (Fig. 7): more than $80 \%$ of this group persisted in their daily habits (the probability of a change decreases by $47 \%$ for this group). Finally, a notable piece of evidence is that being a car user does not emerge as relevant to habit change during the event. As previously explained, these commuters were the ones most affected by the event, and so a greater propensity to change might be expected than for bus and train passengers. On the contrary, car users did not change their

\footnotetext{
${ }^{27}$ The role of communication in probability estimation when facing a risk event has been widely discussed in the literature. It is generally considered that people tend to unduly weight the probability of a risky event (e.g. a terrorist attack) when such events are widely covered by information channels (Sunstein, 2002). At the same time, when an 'affect heuristic' (Slovic et al. 2002) is relevant to routine decision-making, neglecting information and biased probability perception are very likely.
}

the city limits and without additional activities is considered. Therefore, it is particularly interesting to analyse the factors determining a change in travel behaviour for car users. This is done using equation (3):

$$
\begin{aligned}
\ln \left(\frac{P(\text { change } " i ")}{P(\text { nochange })}\right)= & c_{i}+\pi_{i} D(\text { RadioTV })+\theta_{i} D(\text { children }) \\
& +\tau_{i} D(\text { Age } 25 \text { to } 50)+\alpha_{i} D(\text { gender })+\delta_{i}(\text { distance }) \\
& +\eta_{i}(\text { time })+\beta i(\text { riskattitude })+\epsilon
\end{aligned}
$$

Where i\&\#x202F; = \&\#x202F;b1,b2,b3(change options from Fig. 3.

Table 9 shows the estimation results of equation (3), and Table 10 presents the marginal effects of each regressor on the probability of each category. It also reports the predicted conditional probability for each travel choice based on the available data and the estimated coefficients.

In addition to the general findings for the previously discussed equations (the roles of average travelling distance and time and the need to use the car because of daily family-related activities), two results are evident: the role of the information channel and risk aversion. Radio and TV campaigns seem to have been a key factor in forming 


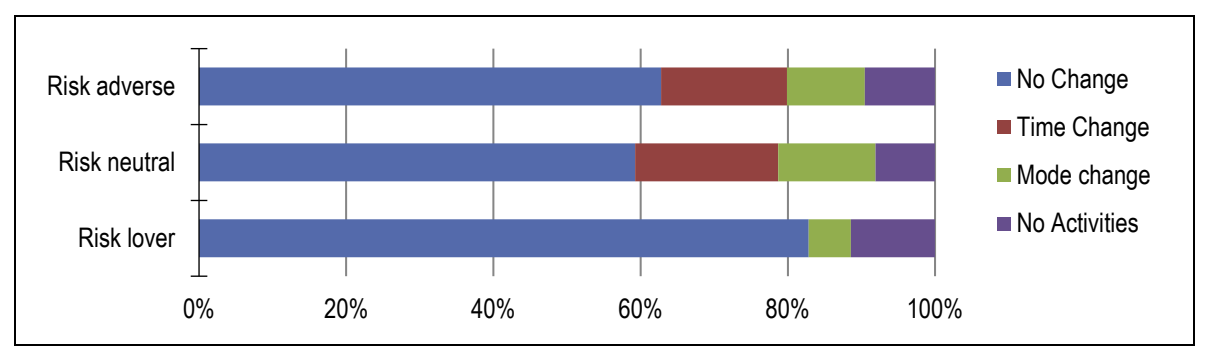

Fig. 7. Behaviour during the big event by risk attitude.

Table 9

Car drivers' behavioural response: multinomial logit estimation (N\&\#x202F; = \&\#x202F;276).

\begin{tabular}{|c|c|c|c|c|}
\hline \multirow[t]{2}{*}{ VARIABLES } & (1) & (2) & (3) & (4) \\
\hline & NoChange & Travel time change & Travel mode change & No Activities \\
\hline \multirow[t]{2}{*}{ RadioTV } & 0 & 0.364 & $0.854 * *$ & $0.885^{*}$ \\
\hline & (0) & $(0.445)$ & $(0.435)$ & $(0.506)$ \\
\hline \multirow[t]{2}{*}{ Children } & 0 & -0.308 & $-0.804 * *$ & -0.130 \\
\hline & $(0)$ & $(0.367)$ & $(0.363)$ & $(0.481)$ \\
\hline \multirow[t]{2}{*}{ Age $25-50$} & 0 & 0.275 & 0.506 & 0.416 \\
\hline & $(0)$ & $(0.380)$ & $(0.397)$ & $(0.497)$ \\
\hline \multirow[t]{2}{*}{ Gender (Male) } & 0 & $-1.154^{* * *}$ & -0.333 & -0.224 \\
\hline & $(0)$ & $(0.344)$ & $(0.359)$ & $(0.458)$ \\
\hline \multirow[t]{2}{*}{ Risk Averse } & 0 & 0.272 & 0.135 & $1.112^{* *}$ \\
\hline & $(0)$ & $(0.362)$ & $(0.381)$ & $(0.432)$ \\
\hline \multirow[t]{2}{*}{ Distance (avg. km) } & 0 & $-0.0309^{* *}$ & $-0.0888 * * *$ & -0.0237 \\
\hline & $(0)$ & $(0.0157)$ & $(0.0216)$ & $(0.0186)$ \\
\hline \multirow[t]{2}{*}{ Time (avg. minutes) } & 0 & $0.0485^{* * *}$ & $0.0671^{* * *}$ & $0.0460 * * *$ \\
\hline & $(0)$ & $(0.0144)$ & $(0.0155)$ & $(0.0172)$ \\
\hline \multirow[t]{2}{*}{ Constant } & 0 & $-1.459 * * *$ & $-1.570^{* * *}$ & $-3.390 * * *$ \\
\hline & $(0)$ & $(0.547)$ & $(0.586)$ & $(0.805)$ \\
\hline Observations & 276 & & & \\
\hline LR $\operatorname{chi}^{2}(18)$ & 66.95 & & & \\
\hline Prob\&\#x202F; > \&\#x202F; $\mathrm{chi}^{2}$ & 0 & & & \\
\hline Pseudo $\mathrm{R}^{2}$ & 0.0983 & & & \\
\hline Log likelihood\&\#x202F; = \&\#x202F; & -306.98165 & & & \\
\hline
\end{tabular}

Notes: robust standard errors in parentheses; *p\&\#x202F; < \&\#x202F;0.1, **p\&\#x202F; < \&\#x202F;0.05, ***p\&\#x202F; < \&\#x202F;0.01.

Table 10

Car drivers' behavioural response: Marginal effects and conditional probabilities.

\begin{tabular}{|c|c|c|c|c|c|}
\hline & AvgChg & Travel time change & Travel mode change & No Activities & No Change \\
\hline RadioTV0 $\geq 1$ & 0.082 & 0.000 & 0.101 & 0.062 & -0.164 \\
\hline Children $0 \geq 1$ & 0.063 & -0.014 & -0.112 & 0.011 & 0.115 \\
\hline Age 25-50 0\&\#x202F; $\geq \& \# x 202 F ; 1$ & 0.048 & 0.019 & 0.054 & 0.023 & -0.096 \\
\hline Gender (Male)0\&\#x202F; $\geq \& \# \times 202 F ; 1$ & 0.093 & -0.186 & 0.004 & 0.013 & 0.169 \\
\hline Risk Averse $0 \geq 1$ & 0.060 & 0.011 & -0.015 & 0.109 & -0.106 \\
\hline Distance (1 additional km) & 0.006 & -0.001 & -0.011 & 0.000 & 0.013 \\
\hline Time ( 1 additional minute) & 0.007 & 0.005 & 0.007 & 0.002 & -0.014 \\
\hline Conditional Probabilities & & Travel time change & Travel mode change & No Activities & No Change \\
\hline $\mathrm{P}(\mathrm{y} \mid \mathrm{x})$ & & 0.216 & 0.178 & 0.102 & 0.504 \\
\hline
\end{tabular}

attitudes to the event: broadcasts promoted changes in travel mode and even a complete withdrawal from commuting (while other 'less pressing' information channels such as newspapers and the web prove to be irrelevant). Risk attitude also exercises an important influence: risk-averse car drivers tend to give up all their activities (daily and working activities) and this is confirmation of the result for the general propensity to change (equation (1)), where we found that risk lovers are the least inclined to change their habits.

To sum up, all this seems to support the 'transport identity' literature: the commuter least inclined to change his habits is the young male risk-loving car driver without daily tasks to accomplish. These subjects, whose propensity for car use is mostly independent of transport policy, seem to not deviate even when the alternative options and incentives are modified. However, we should remember that we are considering a one-off big event affecting the mobility system for just a week and anticipated by a large information campaign asking for general citizen involvement and evoking high risks of congestion. The policy mix seems to have been more effective using the risk-aversion channel than by changing relative GTCs.

\section{Conclusions}

The focus in this paper has been on travel choices after a radical though temporary - reorganization of road and public transport networks due to a big sports event lasting one week. During the event, car use was strongly discouraged by banning car travel in vast areas and other discouraging measures. On the other hand, public transport was enhanced and its use incentivized. As a result of these changes, car 
travel costs and times were significantly modified, as shown by our GTC estimation. Pushed by these monetary and time incentives, car users were expected to largely switch to walking, cycling or public transport.

Contrary to these expectations, commuters' mobility behaviour before and during the event provides some evidence of the resistance to change car use already found in the literature (Innocenti et al., 2013). GTC elasticity and our logit model focusing on the drivers of commuter transport changes give some evidence that behavioural adaptation to new contexts and the typical resistance to change of car commuters is actually influenced by personal characteristics - among which risk attitude plays a role - beside economic incentives. In summary, we can confirm previous findings in the literature: the greatest resistance to changing mobility habits and adapting behaviour during this temporary event is on the part of car drivers, who are also the hardest to target with traditional policies; individual characteristics (gender, age and household structure) have a prevailing influence on adaptation choices, showing that 'affect heuristics processing' dominates and is connected to the perception of uncertainty and risk. Moreover, this evidence confirms that driving a car has an identity-making significance (Steg, 2005). Generally speaking, affective dominance seems to offset important information on alterations to relative journey times and costs during the event, thus discouraging habit changes.

In other words, we have found evidence of the difficulty of influencing car users with economic incentives and rational arguments (e.g. increased relative costs), even in the short term. Awareness that car users systematically deviate from the predictions of rational models is spreading and is leading to the adoption of conceptual frameworks from behavioural economics in the design of policy measures. Therefore, trying to modify the 'addiction' of car drivers towards more sustainable transport modes needs a comprehensive approach using a mix of traditional policies and nudging, as suggested by Sun et al. (2016)

\section{References}

Alós-Ferrer C. and Strack F. (2014), From dual processes to multiple selves: implications for economic behaviour, J. Econ. Psychol. 41 (2014) 1-11.

Avineri, Ben Elia, 2015. Response to travel information: a behavioural review. Transport Rev. 35 (3), 352-377.

Barton, B.K., Morrongiello, B.A., 2011. Examining the impact of traffic environment and executive functioning on children's pedestrian behaviors. Dev. Psychol. 47 (1), $182-191$.

Becker, M., 2004. Organizational routine, a review of the literature. Ind. Corp. Change 13, 643-677.

Cestac, J., Paran, F., Delhomme, P., 2011. Young drivers' sensation seeking, subjective norms, and perceived behavioral control and their roles in predicting speeding intention: how risk-taking motivations evolve with gender and driving experience. Saf. Sci. 49 (3), 424-432.

Dolan, P., Kavetsos, G., Krekel, C., Mavridis, D., Metcalfe, R., Senik, C., Szymanski, S., Ziebarth, N.R., 2017. Quantifying the Intangible Impact of the Olympics Using Subjective Well-being Data. CEP Discussion Paper, pp. 1441.

Fiorio, C.V., Percoco, M., 2007. Would you stick to using your car even if charged? Evidence from Trento, Italy. Transport Rev. 27 (5).

Frey, B., Stutzer, A., 2004. Stress that Doesn't Pay: the Commuting Paradox. Working Paper IZA DP No, pp. 1278.

Friedman, M.S., Powell, K.E., Hutwagner, L., Graham, L.M., Teague, W.G., 2001. Impact of changes in transportation and commuting behaviors during the 1996 Summer Olympic Games in Atlanta on air quality and childhood asthma. J. Am. Med. Assoc. 285 (7), 897-905.

Fujii, S., Kitamura, R., 2003. What does a one-month free bus ticket do to habitual drivers? Transportation 30 (1), 81-95.

Fujii, S., Gärling, T., Kitamura, R., 2001. Changes in drivers' perceptions and use of public transport during a freeway closure: effects of temporary structural change on cooperation in a real-life social dilemma. Environ. Behav. 33 (6), 796-808.
Garcia-Sierra, M., van den Bergh, J.C.J.M., Miralles-Guasch, C., 2015. Behavioural economics, travel behavior and environmental-transport policy. Transport. Res. Part D 41, 288-305.

Garling, T., 1998. Behavioural assumptions overlooked in travel-choice modelling. In: de Dios Ortuzar, J., Hensher, D.A., Jara-Diaz, S. (Eds.), Travel Behaviour Research: Updating the State of Play. Elsevier, Amsterdam-New York, pp. 1-18.

Gärling, T., Axhausen, K.W., 2003. Introduction: habitual travel choice. Transportation $30,1-11$.

Garvill, J., Marell, A., Nordlund, A., 2003. Effects of increased awareness on choice of travel mode. Transportation 30, 63-79.

Goodwin, P., 1977. Habit and hysteresis in mode choice. Urban Stud. 14, 95-98.

Hoffmann, C., Abraham, C., White, M.P., Ball, S., Skippon, S., 2017. What cognitive mechanisms predict travel mode choice? A systematic review with meta-analysis. Transport Rev. 37 (5).

Horrace, W.C., Oaxaca, R.L., 2006. Results on the bias and inconsistency of ordinary least squares for the linear probability model. Econ. Lett. 90 (3).

Innocenti, A., Lattarulo, P., Pazienza, M.G., 2013. Car stickiness, heuristics and biases in travel choice. Transport Pol. 25, 158-168.

Jones, A., Woolley, J., Currie, G., 2015. The London summer 2012 olympic games: threat of disruption and business reaction. Event Manag. 19, 187-210.

Kahneman, D., Tversky, A., 1973. On the psychology of prediction. Psychol. Rev. 80, $237-251$.

Lajunen, T., Summala, H., 2003. Can we trust self reports of driving? Effects of impression management on driver behaviour questionnaire responses. Transport. Res. Part F 6 (2), 97-107.

Lattarulo, P. (Ed.), 2003. I costi ambientali e sociali della mobilità. Franco Angeli, Milano. Legambiente, 2007. Ecosistema Urbano. Roma.

List, J.A., Bailey, C.D., Euzent, P.J., Martin, T.L., 2001. Academic economist behaving badly? A survey on three areas of unethical behaviour. Econ. Inq. 39 (1), 162-170.

Litman, T., 2017. Understanding Transport Demand and Elasticities. Victoria Transport Policy Institute.

Mahmassani, H.S., 1996. Dynamics of commuter behaviour: recent research and continuing challenges. In: Stopher, P., Lee-Gosselin, M. (Eds.), Understanding Travel Behaviour in an Era of Change. Pergamon, Oxford, pp. 279-313.

Murtagh N., Gatersleben, B. and Uzzell, D., (2010), Resistance to Change Regular Travel Behaviour: Self-identity Threat, Previous Travel Behaviour and Psychological Reactance, RESOLVE Working Paper 01-11.

Özkan, T., Lajunen, T., 2006. What causes the differences in driving between young men and women? The effects of gender roles and sex on young drivers' driving behaviour and self-assessment of skills. Transport. Res. Part F 9 (4), 269-277.

Parkes, D., Jopson, A., Marsden, G., 2016. Understanding Travel Behaviour Change during Mega-events: Lessons from the London 2012 Games, vol. 92. Transportation Research Part A: Policy and Practice, pp. 104-119.

Pawlowski, B., Atwal, R., Dunbar, R.I.M., 2008. Sex differences in everyday risk-taking behavior in humans. Evol. Psychol. 6 (1), 29-42.

Rose, G., Marfurt, H., 2007. Travel behaviour change impacts of a major ride to work day event. Transport. Res. Part A 41, 351-364.

Schneider, R.J., 2013. Theory of routine mode choice decisions: an operational framework to increase sustainable transportation. Transport Pol. 25, 128-137.

Slovic, P., Finucane, M.L., Peters, E., MacGregor, D., 2002. Rational actors or rational fools: implications of the affect heuristic for behavioral economics. J. Soc. Econ. 31, 329-342.

Starmer, C., 2000. Developments in non-expected utility theory: the hunt for a descriptive theory of choice under risk. J. Econ. Lit. 38, 332-382.

Steg, L., 2005. Car use: lust and must. Instrumental, symbolic and affective motives for car use. Transport. Res. Part A 39 (2-3), 147-162.

Steg, L., Vlek, C., Slotegraaf, G., 2001. Instrumental-reasoned and symbolic-affective motives for using a motor car. Transport. Res. Part F 4 (3), 151-169.

Sun, L., Karwan, M.H., Changhyun, K., 2016. Incorporating driver behaviors in network design problems: challenges and opportunities. Transport Rev. 36 (4).

Sunstein, C.R., 2002. Probability neglect: emotions, worst cases, and law. Yale Law J. 112 , 61-107.

Van de Kaa, E.J., 2010. Prospect theory and choice behaviour strategies: review and synthesis of concepts from social and transport sciences. Eur. J. Transport Infrastruct. Res. 10 (4), 299-329.

Verplanken, B., Aarts, H., Van Knippenberg, A., Van Knippenberg, C., 1994. Attitude versus general habit: antecedents of travel mode choice. J. Appl. Soc. Psychol. 24, 285-300.

Verplanken, B. and Wood, W. (2006), Interventions to break and create consumer habits, J. Publ. Pol. Market., Vol. 25 (1) Spring 2006, 90-103.

Wardman, M., 2014. Price elasticities of surface travel demand. A meta-analysis of UK evidence. J. Transport Econ. Pol. 48 (3), 367-384. 